\title{
A model to predict patient temperature during cardiac surgery.
}

Citation for published version (APA):

Severens, N. M. W., van Marken Lichtenbelt, W. D., Frijns, A. J., van Steenhoven, A. A., de Mol, B. A., \& Sessler, D. I. (2007). A model to predict patient temperature during cardiac surgery. Physics in Medicine and Biology, 52(17), 5131-5145. https://doi.org/10.1088/0031-9155/52/17/002

Document status and date:

Published: 01/01/2007

DOI:

10.1088/0031-9155/52/17/002

Document Version:

Publisher's PDF, also known as Version of record

Document license:

Taverne

Please check the document version of this publication:

- A submitted manuscript is the version of the article upon submission and before peer-review. There can be important differences between the submitted version and the official published version of record.

People interested in the research are advised to contact the author for the final version of the publication, or visit the DOI to the publisher's website.

- The final author version and the galley proof are versions of the publication after peer review.

- The final published version features the final layout of the paper including the volume, issue and page numbers.

Link to publication

\footnotetext{
General rights rights.

- You may freely distribute the URL identifying the publication in the public portal. please follow below link for the End User Agreement:

www.umlib.nl/taverne-license

Take down policy

If you believe that this document breaches copyright please contact us at:

repository@maastrichtuniversity.nl

providing details and we will investigate your claim.
}

Copyright and moral rights for the publications made accessible in the public portal are retained by the authors and/or other copyright owners and it is a condition of accessing publications that users recognise and abide by the legal requirements associated with these

- Users may download and print one copy of any publication from the public portal for the purpose of private study or research.

- You may not further distribute the material or use it for any profit-making activity or commercial gain

If the publication is distributed under the terms of Article $25 \mathrm{fa}$ of the Dutch Copyright Act, indicated by the "Taverne" license above, 


\section{A model to predict patient temperature during cardiac surgery}

To cite this article: N M W Severens et al 2007 Phys. Med. Biol. 525131

View the article online for updates and enhancements.

\section{Related content} - Measurement of model coefficients of skin Natascha M W Severens, Wouter D van Marken Lichtenbelt, Arjan J H Frijns et al.

Dominant factors affecting temperature rise in simulations of human thermoregulation during RF exposure Ilkka Laakso and Akimasa Hirata

Modelling of temperature and perfusion during scalp cooling

F E M Janssen, G M J Van Leeuwen and A A Van Steenhoven

\section{Recent citations}

- Thermorequlation: A journey from
$\frac{\text { physiology to computational models and }}{\text { the intensive care unit }}$
Kristijan Skok et al
- Research on the human heat transfer
$\frac{\text { model of Chinese pilots and experimental }}{\text { verification of model correctness }}$
Sina Dang et al
- Thermal Simulation of Close-Fitting
$\frac{\text { Sportswear }}{\text { Muhammad Awais et al }}$

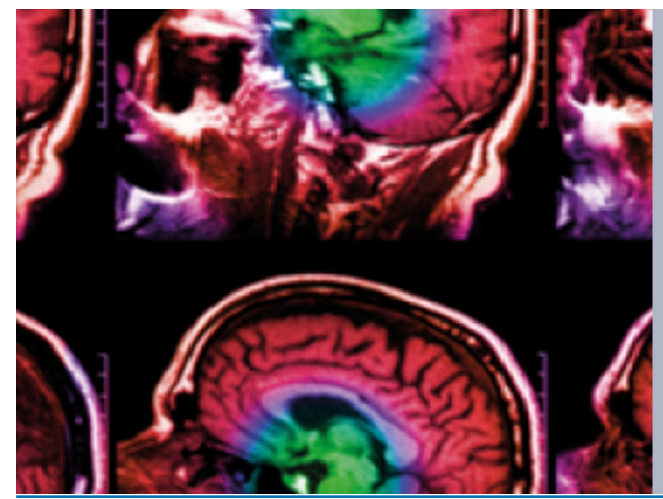

\section{IPEM IOP}

Series in Physics and Engineering in Medicine and Biology

Your publishing choice in medical physics, biomedical engineering and related subjects. Start exploring the collection-download the first chapter of every title for free. 


\title{
A model to predict patient temperature during cardiac surgery
}

\author{
N M W Severens, W D van Marken Lichtenbelt, A J H Frijns, \\ A A van Steenhoven, B A J M de Mol and D I Sessler \\ Department of Mechanical Engineering, Eindhoven University of Technology, PO Box 513, \\ 5600 MB Eindhoven, The Netherlands \\ E-mail: n.m.w.severens@tue.nl
}

Received 10 May 2007, in final form 14 June 2007

Published 7 August 2007

Online at stacks.iop.org/PMB/52/5131

\begin{abstract}
A core temperature drop after cardiac surgery slows down the patient's recuperation process. In order to minimize the amount of the so-called afterdrop, more knowledge is needed about the impaired thermoregulatory system during anesthesia and the effect of different protocols on temperature distribution. Therefore, a computer model has been developed that describes heat transfer during cardiac surgery. The model consists of three parts: (1) a passive part, which gives a simplified description of the human geometry and the passive heat transfer processes, (2) an active part that takes into account the thermoregulatory system as a function of the amount of anesthesia and (3) submodels, through which it is possible to adjust the boundary conditions. The validity of the new model was tested by comparing the model results to the measurement results of three surgical procedures. A good resemblance was found between simulation results and the experiments. Next, a model application was shown. A parameter study was performed to study the effect of different temperature protocols on afterdrop. It was shown that the effectiveness of forced-air heating is larger than the benefits resulting from increased environmental temperature or usage of a circulating water mattress. Ultimately, the model could be used to develop a monitoring decision system that advises clinicians what temperature protocol will be best for the patient.
\end{abstract}

\section{Introduction}

Hypothermia is frequently used to provide protection to vital organs during cardiac surgery. During cardiac procedures with cardiopulmonary bypass, the arterial inflow temperature is imposed by the heat exchanger of the bypass pump. On nearing completion of the surgical procedure, the core temperature is restored to pre-bypass level by adjusting the temperature 


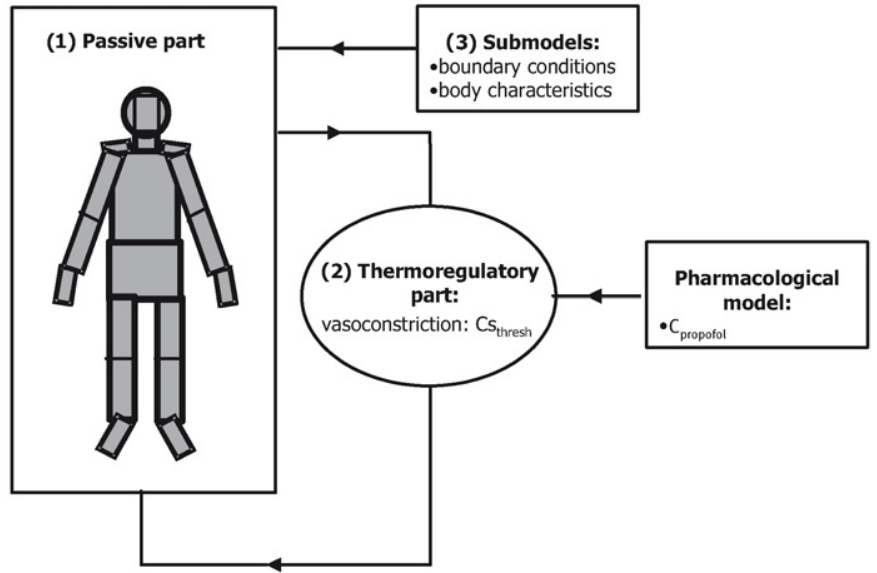

Figure 1. The model consists of three parts: (1) the passive part, (2) the thermoregulatory part, that is coupled to a pharmacological model and (3) a part that gives a description of the boundary conditions and body characteristics.

of the heat exchanging fluid. The major drawback of this warming procedure is that heat is transferred to the core compartment (brain and trunk) more quickly than to the peripheral compartment (arms and legs). After disconnecting the pump, the body is allowed to selfequilibrate. The vasoconstriction response that would occur under normal conditions is impaired by the administered anesthesia (Matsukawa et al 1995). Hence, heat redistribution takes place from the warm core to the colder periphery (Sessler 2000). This causes 'afterdrop' which is a decrease in the temperature of the core organs. Clinicians try to reduce afterdrop as much as possible, as afterdrop may trigger shivering and increase the risk of post-operative complications (Polderman 2004). Circulating water mattresses or forced-air heaters are often used to minimize afterdrop.

To prevent afterdrop, more knowledge is needed about the effect of different protocols on thermoregulatory responses and temperature distribution in anesthetized people. Mathematical whole body temperature models are useful tools to quickly estimate the temperature response of the body due to changes in environmental conditions. However, all previously developed human thermal models (Fiala et al 2001, Stolwijk 1971, Xu and Werner 1997) are restricted to describing the temperature responses of people with an intact thermoregulatory system and do not have enough detail for simulating cardiac surgeries. Those models are therefore not suitable for predicting temperatures of anesthetized patients with impaired thermoregulatory responses. The focus of this paper is to present and validate a whole body thermal model that can predict the temperatures of patients undergoing cardiac surgery. With this computer model, the effects of different temperature protocols or different body composition are easily studied. Ultimately, the model can be used by clinicians to determine the optimal temperature protocol for each individual patient.

\section{Methods}

The computational model that was developed consists of three parts, as shown in figure 1 . The first part is the passive part. This part describes the human geometry in a simplified way and takes into account the heat production and heat transport within the body. Also, 

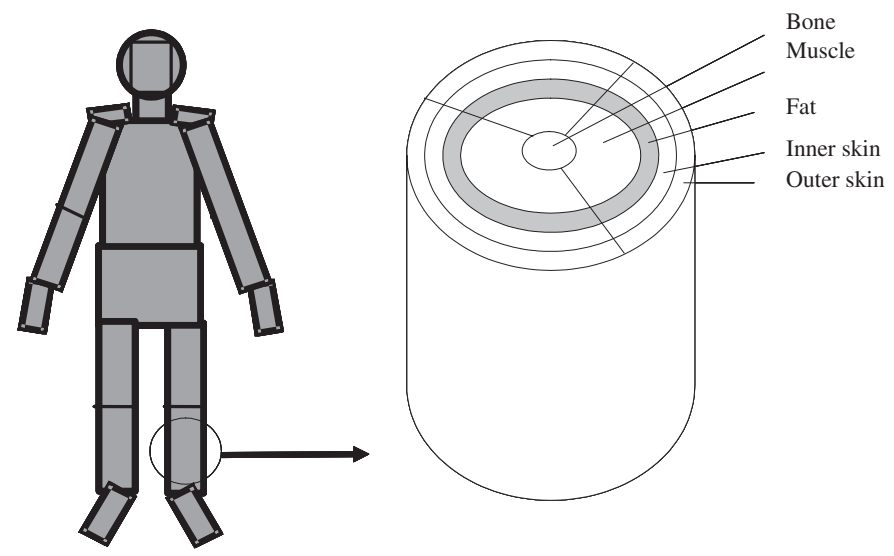

Figure 2. Schematic presentation of the passive whole body model. The right picture gives an impression of how a body part (in this example the leg) is represented in the model.

the heat interaction with the surroundings is accounted for. The second part describes the thermoregulatory reactions during cardiac surgery. In the third part, some features are implemented that are characteristic for cardiac surgery.

\subsection{Part 1: the passive part}

For the development of the passive part of the model, we elaborated the passive model of Fiala et al (1999). This model represented the human body using ten body segments. In the current model, the patient's anatomy is described by 19 body segments (figure 2): a sphere for the head and 18 cylinders representing the trunk and limbs. In the Fiala model peripheral body parts such as hands, feet, arms and legs are modeled as one long segment. The leg segment therefore represented the right upper and lower leg as well as the left upper and lower leg. In the current model, the peripheral body parts are implemented separately, which makes the model more flexible for dealing with non-homogeneous boundary conditions.

All segments consist of multiple concentric homogeneous layers, representing different tissue types. Each tissue layer consists of one or more tissue nodes. The segments are divided into sectors (e.g. anterior, posterior and inferior) on which asymmetric boundary conditions can be imposed. Heat transfer in the tissue is modeled by the Pennes' bioheat equation (Pennes 1948):

$$
\rho c \frac{\partial T}{\partial t}=\nabla k \cdot \nabla T+\rho_{\mathrm{b}} c_{\mathrm{b}} w_{\mathrm{b}}\left(T_{\mathrm{a}}-T\right)+\dot{q}
$$

in which $\rho, c$ and $k$ are the density, specific heat and thermal conductivity, respectively. $T$ is the local tissue temperature and $T_{\mathrm{a}}$ is the temperature of the perfusing blood. $w$ is the volumetric

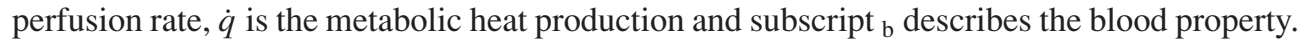
The Pennes' bioheat equation is applied to all tissue nodes using the appropriate material constants, adapted from Fiala et al (1999). The validity and utility of the Pennes' equation has been reviewed by several people (Arkin et al 1994, Stańczyk et al 2007 and van Leeuwen et al 2000). As not much detail is required, the Pennes' model will serve the purpose for the current thermal model.

Heat exchange with the surroundings includes convective, radiative, evaporative and respiratory heat losses. The arterial blood temperature in the human model was calculated by 
assuming that the returning venous blood is mixed in a virtual mixing vessel. The temperature of the mixed venous blood is the arterial temperature for the next time step. In some elements (namely the shoulders, arms, hands, legs and feet), counter current heat exchange takes place between the arteries and veins. In that case, the local temperature $T_{\mathrm{a}}$ in those segments equaled the arterial temperature after counter current heat exchange. Hence, the arterial blood temperature can be different in various body segments.

The partial derivatives with respect to radius were approximated by a central difference scheme. On the interface between two adjoining tissue layers, the boundary conditions are used that impose continuity of temperature and heat flux across the interface. The time derivative in the Pennes' equation was discretized with the Crank-Nicolson method.

\subsection{Part 2: thermoregulation}

Autonomous thermoregulation by the body occurs in several ways: vasodilatation, vasoconstriction, shivering, non-shivering thermogenesis and sweating. When a person is anesthetized, thermoregulation is impaired in a dose-dependent way. While the core temperature is normally strictly regulated around $37{ }^{\circ} \mathrm{C}$, with an interthreshold range of around $0.2{ }^{\circ} \mathrm{C}$, anesthetic drugs can let the interthreshold range increase to $4{ }^{\circ} \mathrm{C}$. Once the thermoregulatory response is triggered, however, the maximum intensity of the reactions are normal (Sessler 1995). The gain of sweating is well preserved during anesthesia (Washington et al 1993), while the gain of vasoconstriction is reduced by at least a factor of 2 (Kurz et al 1995). However, the vasoconstriction gain is still so high that this reduction can be ignored.

The thermoregulatory model that will be used to model cardiac surgery confines to vasoconstriction responses. During general anesthesia, non-shivering thermogenesis does not occur (Sessler 1997) while shivering is prohibited by muscle relaxants.

The metabolism-temperature interplay was modeled according to the $Q_{10}$ relation. This relation states that for every $10^{\circ} \mathrm{C}$ reduction in the tissue temperature, there is a corresponding reduction in cell metabolism with a factor of 2 (Dennis et al 2003, Fiala et al 1999, Janssen et al 2005):

$$
\frac{q_{i}}{q_{i, 0}}=Q_{10}^{\frac{T_{i}-T_{i, 0}}{10^{0^{\circ} \mathrm{C}}}} \quad \text { with } \quad Q_{10}=2
$$

where $q_{i}$ is the metabolic heat production in element $i$. Induction of general anesthesia decreases metabolic heat production by roughly $30 \%$ (Matsukawa et al 1997). This led us to

$$
q_{i, \text { anes }}=0.7 q_{i} .
$$

In non-neutral conditions blood flows vary with changes in regional metabolic rates. This is accounted for by calculating the change in the factor $\Delta \beta_{i}=\rho_{\mathrm{b}} c_{\mathrm{b}} \Delta w_{\mathrm{b}, i}$ as a function of the change in metabolism $\Delta q_{i}$. For this, a proportionality constant $\mu_{\mathrm{b}}=0.932 \mathrm{~K}^{-1}$ was obtained from Fiala (1999):

$$
\Delta \beta_{i}=\mu_{\mathrm{b}} \Delta q_{i} .
$$

By vasoconstriction, the blood vessels in the skin, as well as skeletal muscles, are innervated (Daanen 1997, Stolwijk 1966). The expression for the skin and muscle blood flow is given as

$$
\frac{\beta_{i}}{\beta_{i, 0}}=f \cdot Q_{10}^{\frac{T_{i}-T_{i, 0}}{10^{\circ} \mathrm{C}}} \quad \text { with } \quad Q_{10}=2
$$

with

$$
f=\frac{1}{1+a_{c s, i} \mathrm{Cs}} \quad \text { for the inner skin layer and skeletal muscles, }
$$




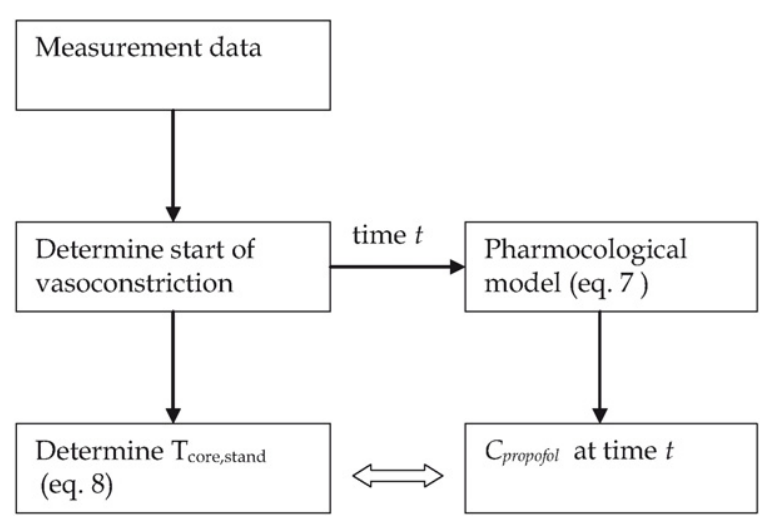

Figure 3. Approach to derive a linear relation between the propofol concentration and vasoconstriction threshold.

in which $a_{c s, i}$ is the distribution factor for vasoconstriction (Fiala et al 2001) and Cs is the vasoconstriction signal. As can be seen in equation (5) the skin and muscle blood flow of a segment are affected by the local temperature $T_{i}$ as well as the centrally controlled vasoconstriction signal Cs.

2.2.1. Model formulation. Opioids and the intravenous anesthetic propofol lower the thresholds for vasoconstriction in linear proportion to increased plasma concentration (Sessler 1997). During cardiac surgery a mixture of anesthetic drugs is administered to the patient. For the development of a vasoconstriction model, we used the anesthetic protocol of our prior measurement series (Severens et al 2007), with propofol as the main anesthetic agent. A linear relationship was derived between the anesthesia concentration and the vasoconstriction threshold. The arterial concentration of propofol was evaluated, by using a pharmacological model, at the time points where vasoconstriction commenced in the measurements. This was done for 15 patients. The vasoconstriction threshold is expressed with the help of the standardized core temperature, as defined by equation (8). In this way, both the core (80\%) and mean skin $(20 \%)$ temperature contribute to the vasoconstriction threshold.

An overview of the approach to formulate a dose-dependent relation for calculating the vasoconstriction is given in figure 3 .

For reducing model complexity, the following simplifications were made: propofol concentration is linearly related to the overall drug concentration and will represent the overall drug concentration, other drugs do not affect propofol and the temperature effect on blood propofol concentration (Sessler 1995) is omitted in the pharmacological model.

2.2.2. Pharmacological model. For predicting drug concentrations a limited number of physiological-based models are available. Upton and Ludbrook (1997) described a simple, but flexible six-compartmental physiological model for calculating blood propofol concentrations in sheep. As body size and weight are comparable, no large differences exist in propofol kinetics and dynamics between sheep and humans. Indeed, Ludbrook and Upton (1997) found close agreement between human and sheep data.

In the pharmacological model, the body was divided into compartments that represent individual organs and tissue groupings. Transport into or out of a compartment was described by a mass balance around that compartment. A lumped model was used, which means that the 
concentration in a compartment is homogeneous and that the physical variables describing the transport processes in the compartment are only time dependent. The general mass balance equation in the lumped compartment model yielded

$$
V_{i} \frac{\partial C_{i}}{\partial t}=x_{\mathrm{in}}+\Sigma Q_{i} C_{i}-x_{\mathrm{ex}}
$$

where $V_{i}$ is the volume of the compartment (1), $C_{i}$ is the propofol concentration in the compartment $\left(\mathrm{mg} \mathrm{l}^{-1}\right), Q_{i}$ is the flow rate $\left(1 \mathrm{~min}^{-1}\right)$ and $x_{\text {in }}$ and $x_{\text {out }}$ denote the injected and excreted drug rates, respectively. From a parameter study, it was observed that the most sensitive parameter in the propofol model was cardiac output. Therefore, the cardiac output value in the model was replaced by the actual value of the cardiac output for the individual patients. The flow rate in a compartment $Q_{i}$ is related to the concentration of propofol (Ludbrook and Upton 1997).

The propofol protocol in the measurement series (Severens et al 2007) comprised a bolus injection of approximately $100 \mathrm{mg}$ propofol in $1 \mathrm{~min}$, followed by continuous injection of about $5 \mathrm{mg} \mathrm{kg}^{-1} \mathrm{~h}^{-1}$ during the actual surgery.

2.2.3. Determining the vasoconstriction threshold. Cheng et al (1995) demonstrated that the cutaneous contribution of mean skin temperature to vasoconstriction is linear. Therefore, it is possible to use the measured skin and core temperatures at each threshold to calculate a core-temperature threshold that would have been observed had the skin been at a standardized temperature (Matsukawa et al 1995):

$$
T_{\text {core, stand }}=T_{\text {core }, \mathrm{obs}}+\left(\frac{\beta}{1-\beta}\right)\left(T_{\text {skin, obs }}-T_{\text {skin, stand }}\right) .
$$

Relation (8) was used for calculating the standardized core temperature at which vasoconstriction was triggered in the measurements. Here, $\beta=0.2$ and $T_{\text {skin,stand }}=35.7^{\circ} \mathrm{C}$ for vasoconstriction (Matsukawa et al 1995). Subscripts stand and obs denote the standardized and observed (measured) temperatures, respectively. The start of vasoconstriction was defined as the moment in time when $T_{\text {finger }}-T_{\text {forearm }}$ showed a sustained decrease. The chest skin temperature was not measured during cardiac surgery. Hence, we modified Hardy-Dubois' seven-point formula to a six-point system (Severens et al 2007) according to

$$
\begin{aligned}
T_{\text {skin }, \text { obs }}=( & 0.07 T_{\text {forehead }}+0.14 T_{\text {posterior forearm }}+0.05 T_{\text {hand }} \\
& \left.+0.19 T_{\text {anterior thigh }}+0.13 T_{\text {anterior calf }}+0.07 T_{\text {foot }}\right) / 0.65
\end{aligned}
$$

2.2.4. Vasoconstriction-propofol relation. At the point in time at which vasoconstriction started, the amount of arterial propofol concentration was calculated with the help of the pharmacological model. At the same time point, the standardized core temperature was determined with (8). Painful stimulation, as produced by surgery, increases the threshold for vasoconstriction by approximately $0.4{ }^{\circ} \mathrm{C}$ (Belani et al 1993). To determine the vasoconstriction threshold at zero concentration propofol, we used the measurement data of Matsukawa et al (1995). Given that vasoconstriction thresholds are linearly related to drug concentration (Matsukawa et al 1995), the following equation for the vasoconstriction threshold was found:

$$
\mathrm{Cs}_{\text {thresh }}=36.69^{\circ} \mathrm{C}-0.82 C_{\text {propofol }} .
$$

Ultimately, the following vasoconstriction model is used:

- If $T_{\text {core,stand }}(t)<\mathrm{Cs}_{\text {thresh }}(t)$ then $\operatorname{Cs}(t)=200$ for the inner skin layer, 75 for muscle.

- If $T_{\text {core,stand }}(t)>\mathrm{Cs}_{\text {thresh }}(t)$ then $\operatorname{Cs}(t)=0$. 


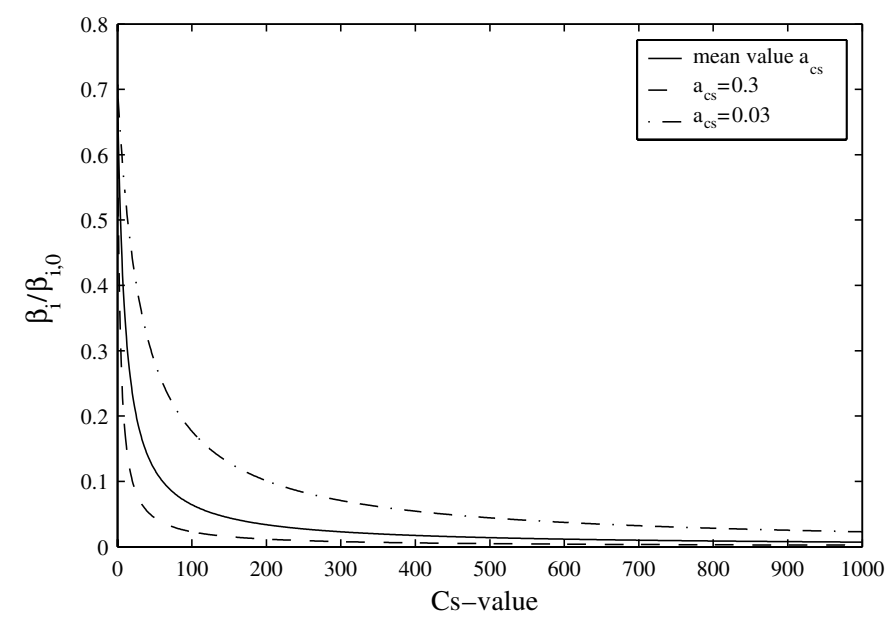

Figure 4. Effect of magnitude $C$ s on the relative perfusion value for $a_{\mathrm{cs}}$-values of $0.03,0.3$ and 0.1 (mean $a_{\mathrm{cs}}$ value). The effect is studied for a $\Delta T$ of $-5^{\circ} \mathrm{C}$.

The choice of setting the Cs-value to 200 is made on the basis of figure 4 and equations (5)(6). The distribution factor for vasoconstriction, $a_{\mathrm{cs}}$, varies roughly between 0.03 and 0.3 , with a mean value of 0.1 . In case the tissue temperature decreases by $5{ }^{\circ} \mathrm{C}$, it is seen that a five times increase in Cs-value, i.e. Cs $=1000$ instead of 200, changes the relative perfusion value by maximal 10\%. The ratio of muscle constriction to skin vasoconstriction (75 and 200, respectively) is based on data presented by Schmidt and Thews (1989).

\subsection{Part 3: submodels}

The final part of the model was a flexible section in which the boundary conditions and body characteristics can be adapted. In this way, an accurate representation of a specific cardiac surgery with cardiopulmonary bypass can be obtained.

2.3.1. Individual body characteristics. In the model, individual subject characteristics were accounted for. The standard geometry was scaled in such a way that body composition data (height, weight, percentage of body fat, body shape) in the model agreed with the body composition of the people from the measurements. Previous simulations have shown that the predictions of a group can be improved by adopting individualized body characteristics (van Marken Lichtenbelt et al 2007).

2.3.2. Heart lung machine. The heat exchanger of the heart lung machine was implemented in the model by using the information given by the manufacturer (COBE Cardiovascular, Inc., Arvada, USA). The effectiveness of the heat exchanger for flow rates of $51 \mathrm{~min}^{-1}$ was $\varepsilon=0.7$. However, in the tube between the heat exchanger and the arterial cannulation site, additional heat loss takes place. Therefore, we set the effectiveness in the model $\varepsilon^{*}$ to 0.5 . Effectiveness then yielded

$$
\varepsilon^{*}=\frac{T_{\mathrm{b}, \text { out }}-T_{\mathrm{b}, \text { in }}}{T_{\mathrm{w}, \text { in }}-T_{\mathrm{b}, \text { in }}}
$$

where $T_{\mathrm{b} \text {,out }}$ is the outgoing blood temperature, $T_{\mathrm{b}, \text { in }}$ is the ingoing blood temperature and $T_{\mathrm{w}, \text { in }}$ is the ingoing water temperature (temperature of the water reservoir). On the next time step, 
$T_{\mathrm{b} \text {,out }}$ was used as the blood pool temperature instead of the venous mixing vessel temperature. Respiratory heat losses were omitted when the patient was on a pump.

2.3.3. Forced-air heating. The heat exchange between the forced-air heating blanket and the patient's skin is given by

$$
q^{\prime \prime}=h_{\mathrm{fa}} \Delta T .
$$

The heat exchange coefficient $h_{\mathrm{fa}}$ defines the efficiency of all the heat exchange mechanisms (radiation, convection and conduction) between the blanket and the patient. From experiments performed with a U-shaped model forced-air blanket (Bair-Hugger, model 560-Cath Lab Blanket, Arizant Healthcare Inc.) an $h_{\mathrm{fa}}$ was found of $16.4 \pm 0.3 \mathrm{Wm}^{-2} \mathrm{~K}^{-1}$ at an outlet air temperature of $43{ }^{\circ} \mathrm{C}$.

2.3.4. The circulating water mattress. Heat transfer between the circulating water mattress and the patient's skin (parts of the head, neck, shoulder, thorax, abdomen, arms, hands, legs and feet) was given by

$$
q^{\prime \prime}=h_{\mathrm{mat}} \Delta T
$$

with a heat transfer coefficient $h_{\text {mat }}$ of $121 \mathrm{Wm}^{-2} \mathrm{~K}^{-1}$ (Bräuer et al 2004a).

2.3.5. Thermal insulation. During surgery the mattress, covered with a cotton drape on which the patient lies, and the sterile surgical drape that covers the patient, provide extra thermal insulation. In the simulation, clothing parameters were enclosed with insulation values of 0.9 clo for the mattress, 0.78 clo for the cotton draping and 0.83 clo for the sterile cover, respectively (Bräuer et al 2004b).

2.3.6. Heat loss through the surgical wound. During the actual surgery, the thorax is opened. Extra heat loss takes place through the opened thorax by means of evaporation, convection and radiation. Ice-cold fluid (saline $0^{\circ} \mathrm{C}$ ) is poured in the open thorax to cease the heart beat. In order to calculate the influence of the open thorax on the heat balance, an extra element was implemented in the model. This brings the total number of elements to 20 . This element consists of 2 layers: a lung layer and a fluid layer. The angle of the segment is estimated to be $75^{\circ}$. Naturally, the anterior part of the existing lung element is reduced by $75^{\circ}$.

We assume that heat transfer only takes place in the radial direction, and not in the tangential direction. Heat exchange between the upper layer in the open thorax element and the surroundings takes place by means of convection, radiation and evaporation. The convective heat flux was given by

$$
q_{\text {convection }}^{\prime \prime}=h_{\mathrm{c}, \operatorname{mix}}\left(T_{A}-T_{\infty}\right)
$$

where $h_{c \text {,mix }}$ is a combined-convection coefficient, $T_{A}$ is the surface temperature of the open thorax element and $T_{\infty}$ is the temperature of the surroundings. The radiative heat flux was described by

$$
q_{\text {radiation }}^{\prime \prime}=\sigma \epsilon \psi\left(T_{A}^{4}-T_{\infty}^{4}\right)
$$

where $\sigma$ is the Stefan-Boltzmann constant, $\epsilon$ is the emission coefficient and $\psi$ is a view factor. The evaporation from a water surface depends on the water temperature and the temperature in the air, the actual humidity of the air and the velocity of the air above the surface. The evaporative heat flux yielded

$$
q_{\text {evaporation, water }}^{\prime \prime}=(25+19 v) \lambda_{\mathrm{H}_{2} \mathrm{O}}\left(x_{\mathrm{s}}-x\right) / 3600
$$



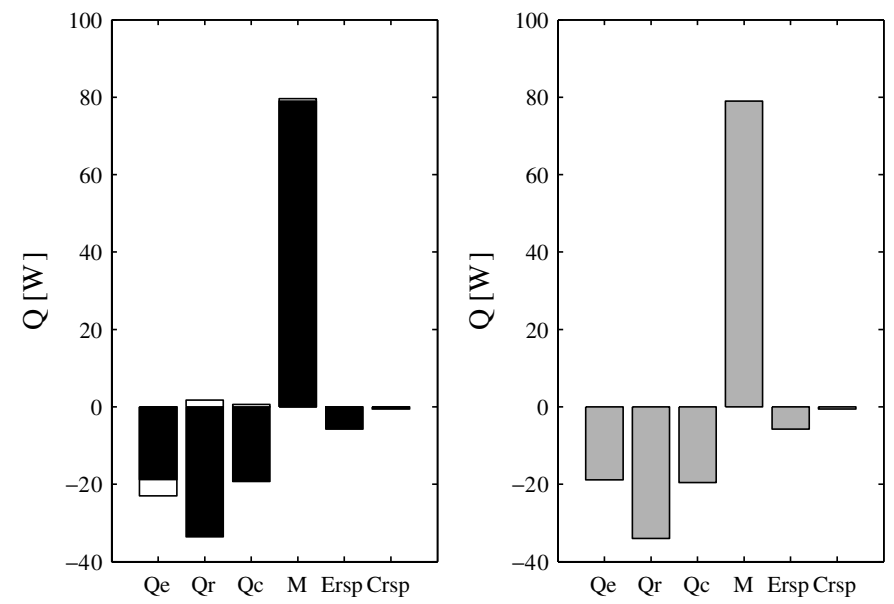

Figure 5. Left: heat flows in a person with an opened thorax at a thermoneutral temperature of $30{ }^{\circ} \mathrm{C}$. White parts represent the heat fluxes through the opened thorax part. Black parts give the heat flows through the 19 other elements. Right: heat flows under normal conditions. In the figures from left to right evaporative heat loss $\left(Q_{\mathrm{e}}\right)$, radiative heat loss $\left(Q_{\mathrm{r}}\right)$, convective heat loss $\left(Q_{\mathrm{c}}\right)$, metabolic heat production $(M)$, evaporative respiratory heat loss $\left(E_{\mathrm{rsp}}\right)$ and dry respiratory heat loss $\left(C_{\mathrm{rsp}}\right)$ are given, respectively.

where $x$ is the humidity ratio in the air $\left(\mathrm{kg} \mathrm{kg}^{-1}\right)$ and $x_{\mathrm{s}}$ is the humidity ratio in saturated air at the same temperature as the water surface $\left(\mathrm{kg} \mathrm{kg}^{-1}\right)$.

To study the effect of the heat loss due to the open thorax, heat fluxes of a person with and without an open thorax were explored at an environmental temperature of $30{ }^{\circ} \mathrm{C}$ (figure 5). The simulations were run for a time period where the heart lung machine was not switched on.

The contribution of the opened thorax to the total heat balance was small. Hence, it would be justified to ignore the heat loss through the open thorax in further simulations.

\section{Results}

\subsection{Validation}

The validity of the new model was tested by comparing the model results to the measurement results of three surgical procedures. One dependent dataset was used: data from an aortic valve surgery without forced-air heating (Severens et al 2007), with which equation (10) was deduced. Thereafter, an independent data set was used from an coronary artery bypass graft surgery performed by Rajek et al (2000). Finally, data was used from an aortic valve surgery in which forced-air heating was used (Severens et al 2007). Part of the latter data was also used to deduce equation (10).

3.1.1. Aortic valve surgery at $30^{\circ} \mathrm{C}$. Core (nasopharyngeal) and mean skin temperature data from an aortic valve surgery (Severens et al 2007) were compared to simulation results. Seven patients (mean body characteristics: weight $80.8 \mathrm{~kg}$, height $172 \mathrm{~cm}$, fat percentage $31.8 \%$ ) were cooled with the help of a heart lung machine to a nasopharyngeal temperature of $30{ }^{\circ} \mathrm{C}$. Toward the end of the surgery, they were rewarmed to a nasopharyngeal temperature 

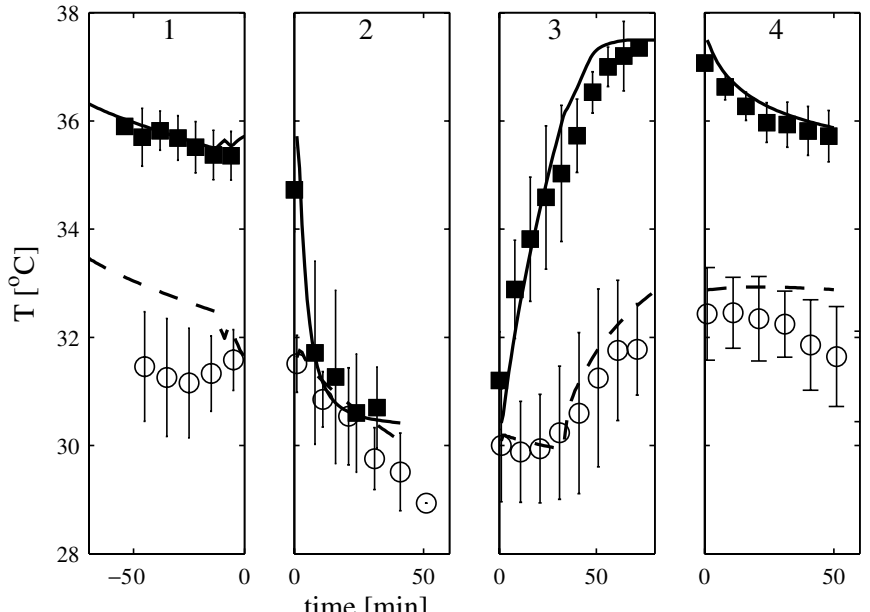

(a)
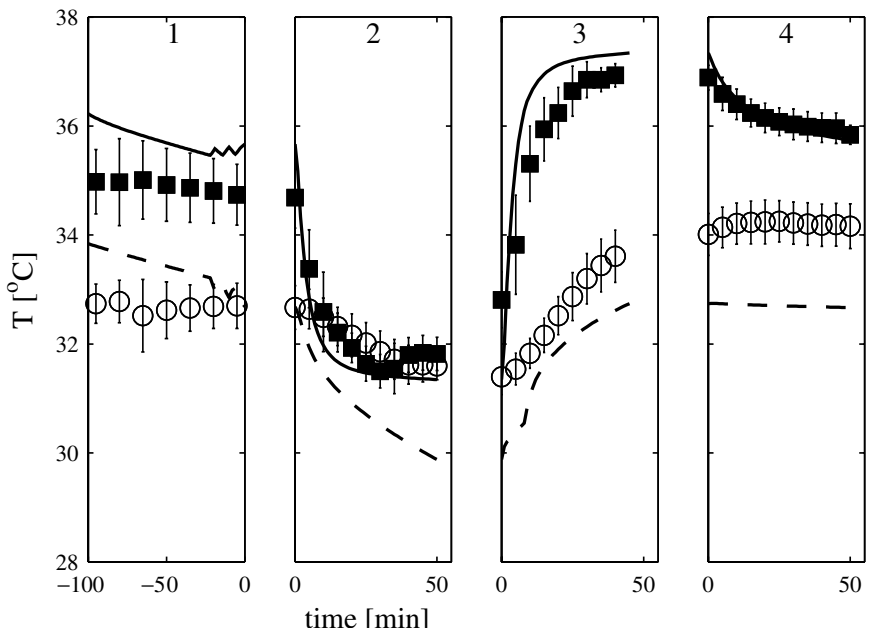

(b)

Figure 6. (a) Aortic valve surgery, (b) coronary artery bypass graft surgery. Simulations consist of four stages: (1) the anesthesia stage, (2) cooling with the heart lung machine, (3) warming with the help of the heart lung machine and (4) the postbypass stage. Symbols ( $\mathbf{\square})$ and (o) represent the experimentally assessed core and mean skin temperatures, respectively. Symbols (-) and (represent the core and mean skin temperatures following the simulation, respectively.

of 37-37.5 ${ }^{\circ} \mathrm{C}$. Bypass flow was kept at $2.41 \mathrm{~min}^{-1} \mathrm{~m}^{-2}$. The fluid-blood gradient was near $1{ }^{\circ} \mathrm{C}$. During cooling, the circulating water mattress was used with a temperature of $30^{\circ} \mathrm{C}$. During the rewarming and postbypass stages, the mattress temperature was approximately $36^{\circ} \mathrm{C}$. No forced-air heater was used. The surrounding temperature was $20^{\circ} \mathrm{C}$.

The calculated and measured core temperature trends agreed very well, see figure 6(a). The errorbars denote the standard deviation of the experimental results in figures 6 and 7 . Simulation results are based on average body characteristics of the patient group.

The skin temperatures initially deviated $2{ }^{\circ} \mathrm{C}$, but eventually the simulation follows the pattern of the measured skin temperature quite well. 

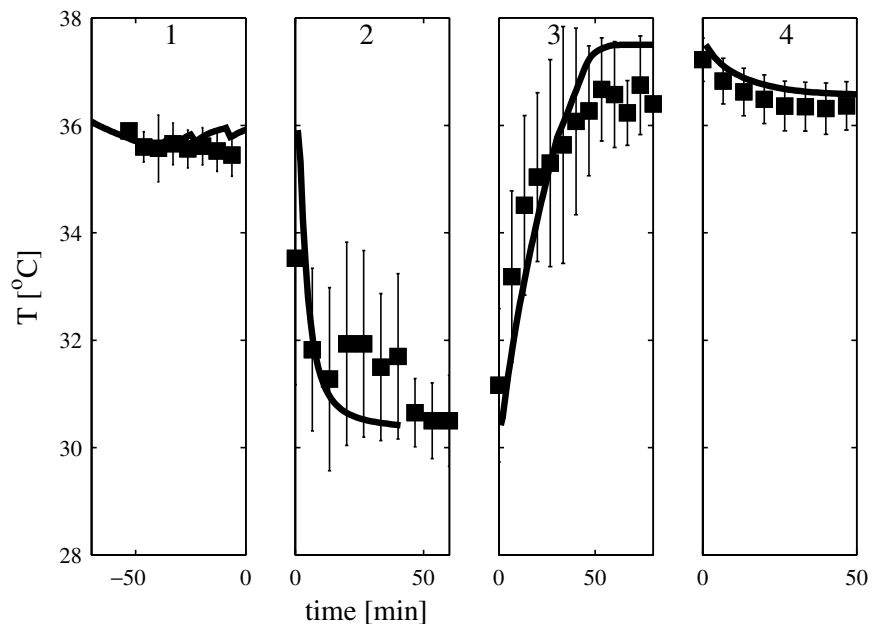

Figure 7. Validation study: an aortic valve surgery, in which a forced-air warmer is used. Simulations consist of four stages: (1) the anesthesia stage, (2) cooling with the heart lung machine, (3) warming with the help of the heart lung machine and forced-air blanket and (4) the postbypass stage with forced-air blanket. Symbol ( $\mathbf{0})$ represents the experimentally assessed core temperature. Symbol (-) represents the core temperature following the simulation.

3.1.2. Coronary artery bypass surgery at $32{ }^{\circ} \mathrm{C}$. Next, a simulation was run with similar surgical conditions as used in the study of Rajek et al (2000). Ten patients (mean body characteristics: weight $77.9 \mathrm{~kg}$, height $171 \mathrm{~cm}$, fat percentage $32.3 \%$ ) were cooled to a nasopharyngeal temperature of $32{ }^{\circ} \mathrm{C}$. The bypass flow was set to $2.51 \mathrm{~min}^{-1} \mathrm{~m}^{-2}$. Towards the end of the surgery, patients were rewarmed to a nasopharyngeal temperature of $37^{\circ} \mathrm{C}$. The initial fluid-blood gradient was near $3{ }^{\circ} \mathrm{C}$. During the rewarming and postbypass stages, the circulating water mattress was used at $39^{\circ} \mathrm{C}$. No forced-air heater was used. The surrounding temperature was kept near $21^{\circ} \mathrm{C}$. The simulation and the measurements agree again reasonably well, see figure 6(b).

The initial temperature differences between the simulation and the experimental results of the coronary artery bypass surgery were larger than for the aortic valve surgery. Unfortunately, the authors did not possess information that could explain the low initial core temperature as found in the experiments of Rajek (2000). However, the initial low core temperature, in combination with the relatively high initial skin temperature, suggests the administration of some premedication, with a vasoactive effect, prior to the start of the measurements.

Regarding the larger deviations between the modeled and measured skin temperatures, it needs to be remarked that the measured value is actually averaged over the values found over various locations on the body. The deviation between those values is much larger than the standard deviation on interindividual values that are shown in figures 6(a) and (b). As the core temperature is our main parameter, the deviation in the skin temperature is not of much concern.

3.1.3. Aortic valve surgery at $30{ }^{\circ} \mathrm{C}$ with forced-air heating. For testing the validity of the model for predicting core temperature afterdrop when using different temperature protocols, simulations with forced-air heating are compared to measurement data in which forced-air heating is used (Severens et al 2007). The protocol was the same as the aortic valve surgery 


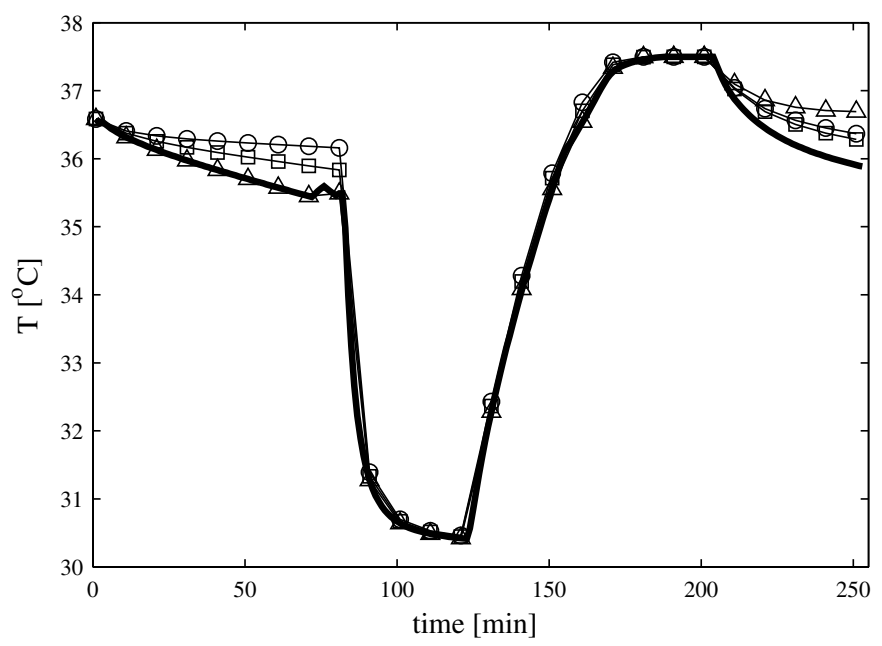

Figure 8. Effect of external temperature protocol on the core temperature. The thick solid lines give the temperature results when the standard aortic valve surgery is simulated. $(\triangle)$ gives the results when forced-air heating is used when simulating the aortic valve surgery. (o) and $(\square)$ give the temperature results when the surrounding temperature is set to $25^{\circ} \mathrm{C}$ and when a heating mattress with a temperature of $40^{\circ} \mathrm{C}$ is used, respectively.

Table 1. Parameter study: the effect of changes in external model parameters.

\begin{tabular}{lll}
\hline Parameter & When & $T_{\text {core }}(t=250 \mathrm{~min})$ \\
\hline Standard condition & Whole surgery & 35.9 \\
Forced-air heater at $43{ }^{\circ} \mathrm{C}$ & Rewarming/postbypass & 36.7 \\
$T_{\infty}=25^{\circ} \mathrm{C}$ & Whole surgery & 36.3 \\
$T_{\text {mattress }}=40{ }^{\circ} \mathrm{C}$ & Whole surgery & 36.4 \\
\hline
\end{tabular}

explained in section 3.1.1, with the addition of a forced-air heater in the rewarming and postbypass stages. The studied group involved eight patients with a mean weight of $78.6 \mathrm{~kg}$, a height of $169 \mathrm{~cm}$ and a fat percentage of $36 \%$. In figure 7, the results of the simulation are shown. Core temperature predictions again agreed well with measurement data.

\subsection{Application: affect of changing external temperature conditions on afterdrop}

It is shown that the model is a strong tool to quickly assess the effect of changing conditions on body temperature. Before exposing patients to a different protocol, the utility of the new protocol can already be verified by simulations. Here, an application example will be given. With the help of the model, the effect of adjusting some external temperature influences is studied. As a standard situation, the aortic valve surgery at $30{ }^{\circ} \mathrm{C}$ is taken. The surgery characteristics and patient morphology of the standard situation are described in section 3.1.1.

We studied three situations to examine the effect of different temperature protocols on the amount of afterdrop: (1) adding a forced-air warmer with an air temperature of $43{ }^{\circ} \mathrm{C}$ in the rewarming and postbypass stages, (2) performing the surgery at an environmental temperature of $25^{\circ} \mathrm{C}$ and (3) using a heating mattress during the whole surgery at $40{ }^{\circ} \mathrm{C}$. Using a forced-air heater considerably improved the core temperature at the end of the surgery, as shown in figure 8 and table 1 . Increasing the temperature of the surrounding also led to a higher core temperature, but was not as effective as forced-air heating. Using a heating mattress resulted 
in a higher core temperature too. The latter method was more effective than increasing the environmental temperature, but not as effective as the use of a forced-air warmer.

\section{Discussion}

For developing the thermoregulatory part of the model a simplified anesthesia model was used. It was assumed that the overall drug concentration was represented by the momentary propofol concentration, which was the main drug in our previous measurement series (Severens et al 2007). In reality, a mixture of drugs is administered to the patient. This might lead to some drug-drug interaction. Nonetheless, the typical concentrations of anesthetics used during cardiac surgery roughly increase the interthreshold in the same way (Sessler 1997). Therefore, the reduced propofol model will suffice as a first approach. It would have been better in case the arterial concentration of propofol was also experimentally assessed, but unfortunately no blood samples were taken during the measurements.

The propofol model was based on a compartmental physiological model for calculating the propofol concentration in sheep. As Ludbrook and Upton (1997) found close agreement between human and sheep data, no large errors are expected when using this model for calculating the drug concentration. This was also tested by comparing results obtained with the sheep model, as used in this paper, with results presented by Levitt and Schnider (2005). The concentration trends of the sheep model showed good agreement with the predictions of Levitt and Schnider. For the current application, the sheep model will therefore be appropriate.

It was shown that the contribution of the open wound to the total heat balance was small during cardiac surgery (section 2.3.6). During cardiac surgery, cold saline is poured in the open thorax. This substantially reduces the effect of evaporative heat losses in comparison to other interventions with a surgical incision, like the rabbit study of Roe (1971). Therefore, direct extrapolation from our findings to other situations is not possible. However, the model offers possibilities to mimic other situations. It would therefore also be possible to predict heat losses in other surgical interventions which cannot yet be assessed experimentally in humans, because of technical difficulties (Sessler 2000).

At this moment there is an abrupt transition between vasoconstriction and no vasoconstriction. Plans exist to develop a smoother (temperature-dependent) relation for Cs with the help of perfusion-temperature measurements that will be collected in a follow-up study with healthy volunteers. Although the current vasoconstriction model is not smooth, no large errors are expected when simulating a cardiac surgery; according to our simulations, vasoconstriction was not triggered until the cooling stage commenced, and stopped before the end of the rewarming stage. In these periods, temperature changed very fast, which implies that the Cs-values would also have changed really quickly in the case where a smooth model had been used.

In a validation study, it was shown that good agreement exists between simulation results obtained with our computational model and experimental results. Measurement data from Severens et al (2007) and those from Rajek et al (2000) were compared to simulation results. The largest deviations between simulation and experiments in both cases occurred in the early stage of the surgery. This can be attributed to the uncertainties in initial conditions. The starting point in all simulations was that patients were in a thermoneutral condition before the surgery. The thermoneutral temperature distribution was determined by calculating the equilibrium temperature distribution of a naked person at an environmental temperature of $30{ }^{\circ} \mathrm{C}$. In reality, patients had a history of non-thermoneutral conditions.

Mean skin temperature predictions seemed to be not as good as core temperature predictions. Temperature varies across the surface of the skin. Mean skin temperature is 
therefore obtained by taking the mean of local temperatures weighted according to the relative surface area, they are supposed to characterize. However, local skin temperatures often do not represent regional skin sites very well. Concurrently, interindividual variations can be large. Core temperature is only represented by the nasopharyngeal temperature, and therefore regional differences do not play a role in this quantity. Moreover, the model is quite sensitive to the boundary conditions that are imposed. Probably, the model predictions (especially skin temperature) will improve, in case experimental boundary conditions (e.g. surrounding temperature, clothing insulation, air flow, etc) are assessed in more detail. For example, for obtaining a correct description of heat distribution in the periphery, when using forced-air heaters, a more complex heat transfer model is required, as follows from perfusion data taken by Severens et al (2007).

\section{Conclusion}

A whole body thermal model was presented that can be used to predict the temperature responses of patients who undergo cardiac surgery. In contradiction to other existing models, the current model encloses an active part that gives a description of the impaired thermoregulation during cardiac surgery. Therefore, the present model is a substantial supplement to the existing models. Validation studies showed that the new model resembled the temperature responses of patients undergoing different cardiac procedures. The model is also a useful tool to study the effects of different — and sometimes adjustable — parameters on the patient's temperature distribution. The latter information is especially useful when temperature intervention is needed during surgery. With the help of the current model, several protocols were assessed. From a parameter study it became clear that using a forced-air heater, with a temperature of $43{ }^{\circ} \mathrm{C}$, increases the core temperature at the end of the surgery by $0.8{ }^{\circ} \mathrm{C}$, compared to the standard aortic valve procedure. Usage of a forced-air heater prevailed the effect of a $5{ }^{\circ} \mathrm{C}$ increase in the environmental temperature, and also prevailed over the use of a $40{ }^{\circ} \mathrm{C}$ circulating water mattress.

In conclusion, the model employed in this paper has two major applications. On the one hand, predictions can be made of the patient's temperature distribution during cardiac surgery. On the other hand, it can be used as a test tool for quickly evaluating influences of different protocols on the transient temperature distribution. The ultimate application for this model would be to use it as a monitoring tool, that detects the temperature of the patient, and eventually advises clinicians if, and what kind of thermal intervention is needed to reduce afterdrop.

\section{References}

Arkin H, Xu L X and Holmes K R 1994 Recent development in modeling heat transfer in blood perfused tissue IEEE Trans. Biomed. Eng. 41 97-107

Bräuer A, Pacholik L, Perl T, English M J M, Weyland W and Braun U 2004a Conductive heat exchange with a gel-coated circulating water mattress Anesth. Analg. 99 1742-6

Bräuer A, Perl T, Uyanik Z, English M J M, Weyland W and Braun U 2004b Perioperative thermal insulation: minimal clinically important differences? Br. J. Anaesth. $92836-40$

Belani K, Sessler D I, Sessler A M, Schroeder M, McGuire J, Merrifield B, Washington D E and Moayeri A 1993 Leg heat content continues to decrease during the core temperature plateau in humans anesthetized with isoflurane Anesthesiology 78 856-63

Cheng C, Matsukawa T, Sessler D I, Ozaki M, Kurz A, Merrifield B, Lin H and Oloffsom P 1995 Increasing mean skin temperature linearly reduces the core-temperature thresholds for vasoconstriction and shivering in humans Anesthesiology 82 1160-8 
Daanen H A M 1997 Central and peripheral control of finger blood flow in the cold PhD Thesis Vrije Universiteit, Amsterdam

Dennis B H, Eberhart R C, Dulikravich G S and Radons S W 2003 Finite-element simulation of cooling of realistic 3D human head and neck J. Biomech. Eng. $125832-40$

Fiala D, Lomas K J and Stohrer M 1999 A computer model of human thermoregulation for a wide range of environmental conditions: the passive system J. Appl. Phys. 87 1957-72

Fiala D, Lomas K J and Stohrer M 2001 Computer prediction of human thermoregulatory and temperature responses to a wide range of environmental conditions Int. J. Biometeorol. 45 143-59

Janssen F E M, van Leeuwen G M J and van Steenhoven A A 2005 Modelling of temperature and perfusion during scalp cooling Phys. Med. Biol. 50 4065-73

Kurz A, Xiong J, Sessler D I, Dechert M, Noyes K and Belani K 1995 Desflurane reduces the gain of thermoregulatory arterio-venous shunt vasoconstriction in humans Anesthesiology 83 1212-9

Levitt D G and Schnider T W 2005 Human physiologically based pharmacokinetic model for propofol BMC Anesthesiol. 54

Ludbrook G L and Upton R N 1997 A physiological model of induction of anaesthesia with propofol in sheep: 2. Model analysis and implications for dose requirements Br. J. Anaesth. 79 505-13

Matsukawa T, Hanagata K, Ozaki M, Iwashita H, Koshimizu M and Kumazawa T 1997 I.m. midazolam as premedication produces a concentration-dependent decrease in core temperature in male volunteers $B r . J$. Anaesth. 78 396-9

Matsukawa T, Kurz A, Sessler D I, Bjorksten A R, Merrifield B and Cheng C 1995 Propofol linearly reduces the vasoconstriction and shivering thresholds Anesthesiology 82 1169-80

Pennes H H 1948 Analysis of tissue and arterial blood temperatures in the resting human forearm J. Appl. Physiol. $193-122$

Polderman K H 2004 Application of therapeutic hypothermia in the intensive care unit. Opportunities and pitfalls of a promising treatment modality_-part 2. Practical aspects and side affects Intens. Care Med. 30 757-69

Rajek A, Lenhardt R, Sessler D I, Brunner G, Haisjackl M, Kastner J and Laufer G 2000 Efficacy of two methods for reducing postbypass afterdrop Anesthesiology 92 447-56

Roe C F 1971 Effect of bowel exposure on body temperature during surgical operations Am. J. Surg. 122 13-5

Schmidt R F and Thews G (ed) 1989 Human Physiology 2nd edn (Berlin: Springer)

Sessler D I 1995 Deliberate mild hypothermia J. Neurosurg. Anesthesiol. 7 38-46

Sessler D I 1997 Mild perioperative hypothermia N. Engl. J. Med. 336 1730-7

Sessler D I 2000 Perioperative heat balance Anesthesiology 92 587-96

Severens N M W, Marken van Lichtenbelt W D, van Leeuwen G M J, Frijns A J H, van Steenhoven A A, de Mol B A J M, van Wezel H B and Veldman D J 2007 Effect of forced-air heaters on perfusion and temperature distribution during and after open heart surgery Euro. J. Cardiothoracic Surg. submitted

Stańczyk M, van Leeuwen G M J and van Steenhoven A A 2007 Discrete vessel heat transfer in perfused tissue-model comparison Phys. Med. Biol. 52 1-13

Stolwijk J A J 1971 A mathematical model of physiological temperature regulation in man NASA Contractor Report CR-1855 (Washington, DC: Aeronautics and Space Administration)

Stolwijk J A J and Hardy J D 1966 Temperature regulation in man-a theoretical study Pflügers Arch. Gesamte Physiol. Menschen Tiere. 291 129-62

Upton R N and Ludbrook G L 1997 A physiological model of induction of anaesthesia with propofol in sheep: 1. Structure and estimation of variables Br. J. Anaesth. 79 497-504

van Leeuwen G M J, Hand J W, Lagendijk J J W, Azzopardi D V and Edwards A D 2000 Numerical modeling of temperature distributions within the neonatal head Pediatr. Res. 48 351-6

van Marken Lichtenbelt W D, Frijns A J H, van Ooijen A M J, Fiala D, Kester A M and van Steenhoven A A 2007 Validation of an individualized model of human thermoregulation for predicting responses to cold air Int. J. Biometeorol. 51 169-79

Washington D, Sessler D I, Moayeri A, Merrifield B, Prager M, McGuire J, Belani K, Hudson S and Schroeder M 1993 Thermoregulatory responses to hyperthermia during isoflurane anesthesia in humans J. Appl. Physiol. $7482-7$

Xu X and Werner J 1997 A dynamic model of the human/clothing/environment-system Appl. Hum. Sci. 16 61-75 